\title{
THE EFFECT OF MICROSTRUCTURAL SCALE ON HARDNESS OF MoSi2-Mo5Si3 EUTECTICS
}

\author{
D. P. Mason and D. C. Van Aken \\ Department of Materials Science and Engineering \\ The University of Michigan \\ Ann Arbor, MI 48109 \\ (Received November 10, 1992) \\ Introduction
}

Recently there has been a renewed interest in molybdenum disilicide (MoSi2) as a possible high temperature structural material. Extensive research on the mechanical behavior of monolithic and MoSi2-based materials is being performed and structure property relationships are beginning to be addressed (e.g. 1-4). Of particular interest to this study is the relationship between hardness and the microstructural scale of the MoSi2. It has previously been shown that some intermetallic compounds, like $\mathrm{FeCo}, \mathrm{FeCo}-\mathrm{V}$ and $\mathrm{Ni} 3 \mathrm{Mn}$, (5) obey the Hall-Petch relationship and Tiwari et al (6) have suggested the same for MoSi2. In the case of MoSi2, the reported data cover a range of grain diameters between 7 and $30 \mu \mathrm{m}(1,2,7-12)$ and this information is tabulated with the reported hardness values in Table I. It is apparent that a smaller grain size is associated with higher hardness values, but the amount of data is too limited to suggest a specific structure-property relationship. Although the hardness and grain diameter database for monolithic $\mathrm{MoSi}_{2}$ is small, a wide range of values have been reported for $\mathrm{MoSi}_{2}-\mathrm{SiC}$ particulate composites (13). This data shows that as the $\mathrm{SiC}$ content is increased the hardness also increased and the grain size of the MoSi2 decreased. It is interesting to speculate that some of the increased hardness may have resulted from a decreasing grain size.

Gibala et al have recently shown that the hardness of MoSi2-Mo5Si3 eutectics can be significantly increased by the additions of 0.35 atomic percent erbium (2). In this case several notable microstructural changes resulted from the rare earth additions and they include: 1 . deoxidization of the liquid melt prior to solidification, 2 . refinement of the eutectic structure, and 3. formation of a small volume fraction of $\mathrm{Er}_{2} \mathrm{Mon}_{3} \mathrm{Si}$. Also, the hot hardness of the erbium treated material was significantly greater than the binary alloy (see FIG. 1) but no difference in flow stress was observed during compression testing. Thus, the purpose of this paper is to determine if the hardness can be affected by the microstructural scale and to determine the functional relationship between the lamellar spacing and hardness. Unlike powder processed composite materials a greater variety of microstructural scales can be produced by controlling the solidification rate and yet maintain the same concentration of the reinforcement. Furthermore, it has also been shown that the microstructural scale of the $\mathrm{MoSi}_{2}-\mathrm{Mo5}_{5} \mathrm{Si}_{3}$ eutectic can be increased by increasing the erbium concentration from 0.35 to 1.75 atomic percent (14).

\section{Experimental Procedure}

A variety of processing paths were used in this study to produce the eutectic composition of 55.5 volume percent MoSi2 and 44.5 volume percent Mo5Si3. Arc-cast materials were prepared from high purity elemental Mo (99.99\%) and Si $(99.9999 \%)$ powders (designated as ACP) and these produced the finest microstructures with a eutectic spacing on the order of $1 \mu \mathrm{m}$. Also, arc-cast materials (designated as AC) were produced from MoSi2 powders contaminated with $\mathrm{SiO}_{2}$ (3.61 at \% as determined by Johnson Matthey) and elemental Mo (99.95\%) powders. Erbium chips were added to the $\mathrm{MoSi}_{2}$ and Mo powders to produce eutectic alloys with 0.35 to 1.75 atomic percent erbium. A nominal weight of 15 grams was used to produce each arc-cast button. Directionally Solidified materials were produced from elemental Mo (99.99\%) and Si (99.9999\%) powders and two samples (designated as DS) were processed using a Bridgman technique in a Centorr model CG-2.5X2-3X3-W-A-D6A3-A-22 furnace at a temperature of $1925^{\circ} \mathrm{C}$ and at speeds of $10.25 \mathrm{~mm} / \mathrm{h}$ and $8.9 \mathrm{~mm} / \mathrm{h}$. Two additional alloys (designated as DSG) were directionally solidified at McMaster University using a tri-arc furnace and a Czochralski method. Both DSG samples were pulled at $39 \mathrm{~mm} / \mathrm{h}$, but one alloy contained 0.35 at \% erbium. For comparison, two powder processed composites (designated as HP) were prepared from elemental Mo (99.95\%) and the Johnson Matthey MoSi2 powders. One of these compacts contained 


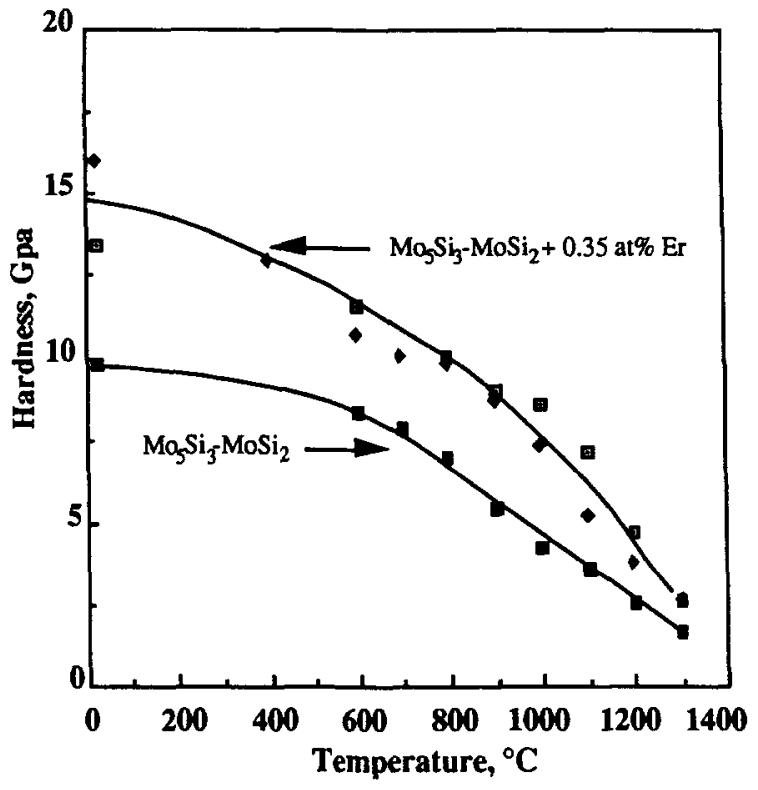

FIG. 1 Hot hardness tests of the arc-cast Er-modified and untreated eutectic alloys. Results show an increased hardness for the Er-modified alloys at all test temperatures.

0.35 at \% erbium which was added during ball milling. These materials were consolidated by hot pressing at $1625^{\circ} \mathrm{C}$ for 2 hours under a pressure of $23 \mathrm{MPa}$. Nominal densities of $95-97 \%$ of the theoretical were achieved with microstructures consisting of MoSi2 and Mo5Si3. An arccast button of $\mathrm{Mo5Si}_{3}$ was also produced from the elemental Mo and Si powders.

The MoSi2 spacing, or grain diameters, of each alloy was determined using a conventional linear intercept method. Room temperature hardness measurements were taken on a Zwick micro-hardness tester with a standard Vickers pyramid indentor using loads of $0.5 \mathrm{~kg}$ to $1 \mathrm{~kg}$. Uncertainties in these measurements were determined by assuming log-normal statistics and the reported error bars represent a $68 \%$ confidence level, i.e. one standard deviation.

\section{Results}

The microstructural scale of the MoSi2 phase was found to vary as a function of both processing path and erbium concentration. In general, the scale was found to increase with decreasing solidification rate and increasing erbium content (see FIG. 2). (Note that the micrographs presented in figures 2 and 3 are of transverse sections normal to the growth direction.) Interlamellar spacing for the arc-cast materials ranged from $0.93 \mu \mathrm{m}$ for the eutectic

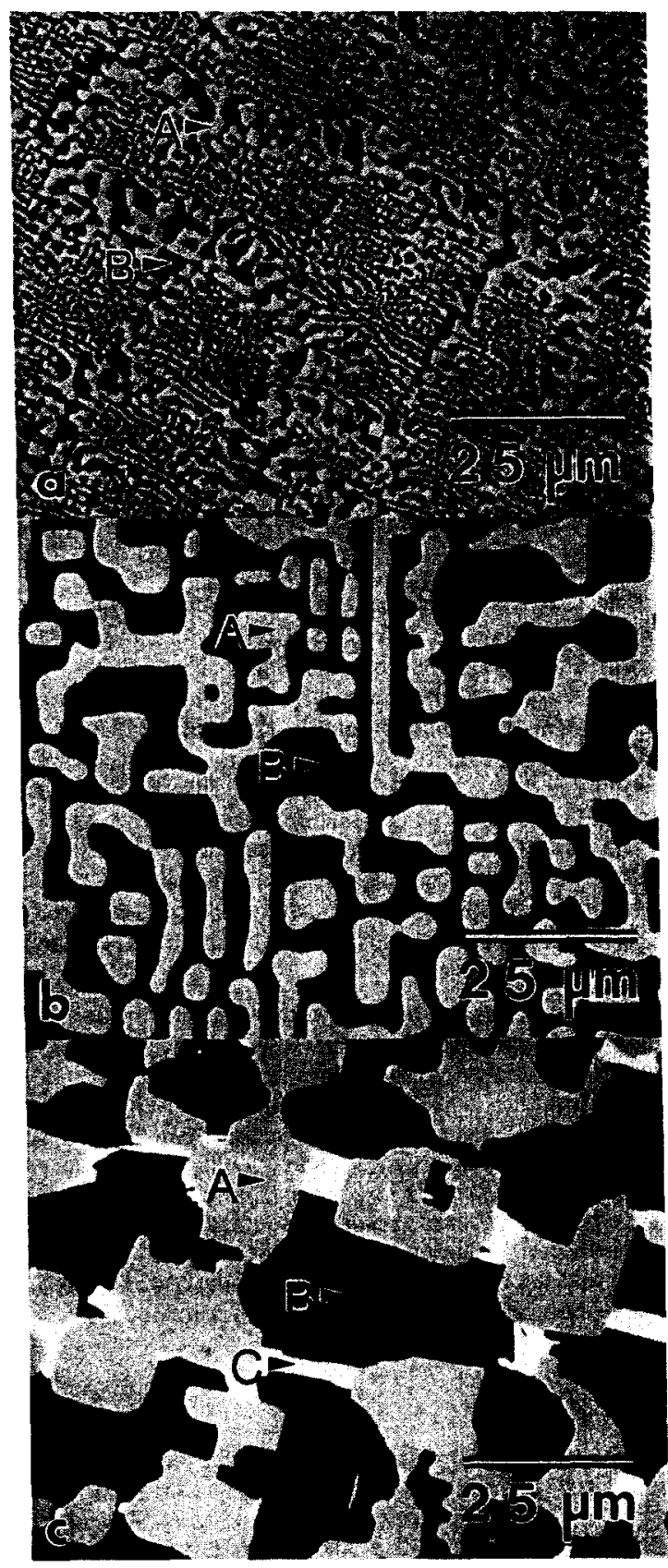

FIG. 2 Backscattered electron micrographs showing the various scales of eutectic microstructure used for hardness testing: a) Alloy ACP b) Alloy DS c) Alloy DSG + 0.35 at $\% \mathrm{Er}$. (phase identification $\mathrm{A}-\mathrm{Mo5} \mathrm{Si}, \mathrm{B}-\mathrm{MoSi} 2$ and $\mathrm{C}$ $\mathrm{Er}_{2} \mathrm{Mo}_{3} \mathrm{Si}_{4}$ ) 


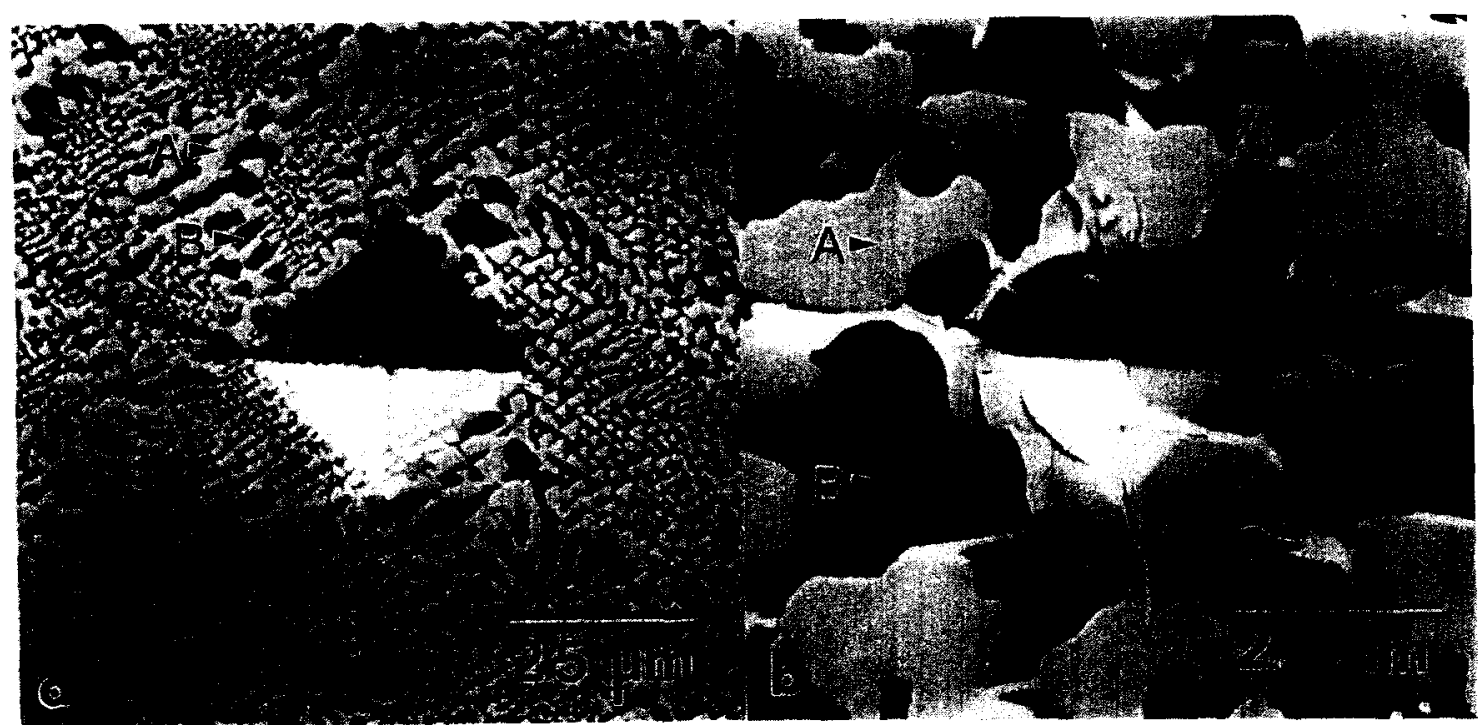

FIG. 3 Backscattered electron micrographs showing vickers pyramid indentations in a) alloy ACP and b) alloy DSG + 0.35 at \% Er under loads of 1.0 and $0.5 \mathrm{Kg}$, respectively. Note that, although a larger applied load was used on the ACP alloy the crack lengths were similar to that of the DSG alloy, indicating that the fracture toughness may be increased as the lamellar spacing is decreased. (phase identification A-Mo5Si3, B-MoSi2 and C-Er2Mo3 $\mathrm{Si}_{4}$ )

produced from high purity $\mathrm{Mo}$ and $\mathrm{Si}$ powders to a spacing of $9.2 \mu \mathrm{m}$ for $\mathrm{SiO}_{2}$ contaminated samples. Lamellar spacing increased continuously with increasing erbium content and ranged from $0.93 \mu \mathrm{m}$ in the binary alloy to $3.4 \mu \mathrm{m}$ at a concentration of 1.4 atomic percent erbium. A third intermetallic phase was also observed in the erbium treated material and has been previously identified as $\mathrm{Er}_{2} \mathrm{Mo}_{3} \mathrm{Si}_{4}$ (14). In directionally solidified alloys the lamellar spacing ranged from 2.04 to $11.55 \mu \mathrm{m}$ and from 5.01 to $6.56 \mu \mathrm{m}$ for the Czochralski and Bridgman techniques, respectively. Again the addition of erbium had the effect of increasing the lamellar spacing when directionally solidified by the Czochralski method. Hot pressing produced a MoSi2 grain diameter of $8 \mu \mathrm{m}$ in the binary alloy whereas the erbium treated alloy produced a $6.1 \mu \mathrm{m}$ grain diameter. Both plastic deformation and cracking were evident in the vicinity of the indentation after microhardness testing. The load was varied to maintain an equivalent observed crack length after each test (see FIG. 3) and a summary of the processing path, MoSi2 scale, and hardness is provided in Table II.

A correlation between hardness and the microstructural scale was found using the Hall-Petch relationship (see FIG. 4). In this study the nominal MoSi2 width of the lamellar eutectic was substituted for the grain diameter and a linear correlation was observed. Also plotted are the room temperature hardness values for the monolithic MoSi2 materials reported in Table $I$. It is interesting to note that these materials also fall within the same range as the eutectics An intrinsic hardness of the $\mathrm{MoSi} 2-\mathrm{MosSi} 3$ eutectic was determined from the Hall-Petch graph as $8.5 \pm 1.5 \mathrm{GPa}$ and also calculated as a weighted average of MoSi2 and Mo5Si3 to be $10.6 \mathrm{GPa}$ based upon the hardness of $11.5 \mathrm{GPa}$ for our arc-cast $\mathrm{Mo5Si}_{3}$ and $9.86 \mathrm{GPa}$ reported for single crystal $\mathrm{MoSi}_{2}$ (15). It should be noted that the reported hardness values for single crystal MoSi2 were a function of indentation load and ranged between 9.86 to $18.74 \mathrm{GPa}$.

\section{Discussion}

In the present study the hardness of the MoSi2-Mo5Siz eutectic was found to be a function of the lamellar spacing and followed a Hall-Petch relationship where the hardness was dependent upon the scale of the MoSi 2 lamellae. These results should be valid since, as demonstrated by Boldt, Embury and Weatherly (15), considerable dislocation activity can be generated at room temperature in the hydrostatic stress field under the indentor. Also, we specifically adjusted the load to obtain an equivalent radial crack length and thus, the fracture contribution should be equivalent between tests. These results are significant as the Hall-Petch relationship is based on dislocation plasticity and in the case of these eutectic materials the Mo5Si3 phase appears to behave as the impenetrable barrier. Thus, Mo5Si3 should be 
TABLE I

Hardness and Grain Size Values of Monolithic $\mathrm{MoSi}_{2}$

\begin{tabular}{|c|c|c|}
\hline $\begin{array}{c}\text { Hardness } \\
(\mathrm{GPa})\end{array}$ & Grain Size & Ref. \\
\hline 11.80 & not specified & 1 \\
\hline 8.38 & 30 um & 2 \\
\hline 10.78 & not specified & 6 \\
\hline 11.84 & 18 um & 7 \\
\hline 8.58 & not specified & 8 \\
\hline 10.13 & & \\
10.37 & not specified & 9 \\
\hline 12.42 & 18 um & 11 \\
\hline 8.70 & $7 \pm 4$ um & 12 \\
\hline 9.60 & 1 um & \\
\hline $13.9 *$ & 28 um & 13 \\
\hline 9.25 & $\begin{array}{c}\text { single } \\
\text { crystal }\end{array}$ & 15 \\
\hline 9.86 & & \\
\hline
\end{tabular}

$*(\mathrm{Mo}, \mathrm{W}) \mathrm{Si}_{2}$

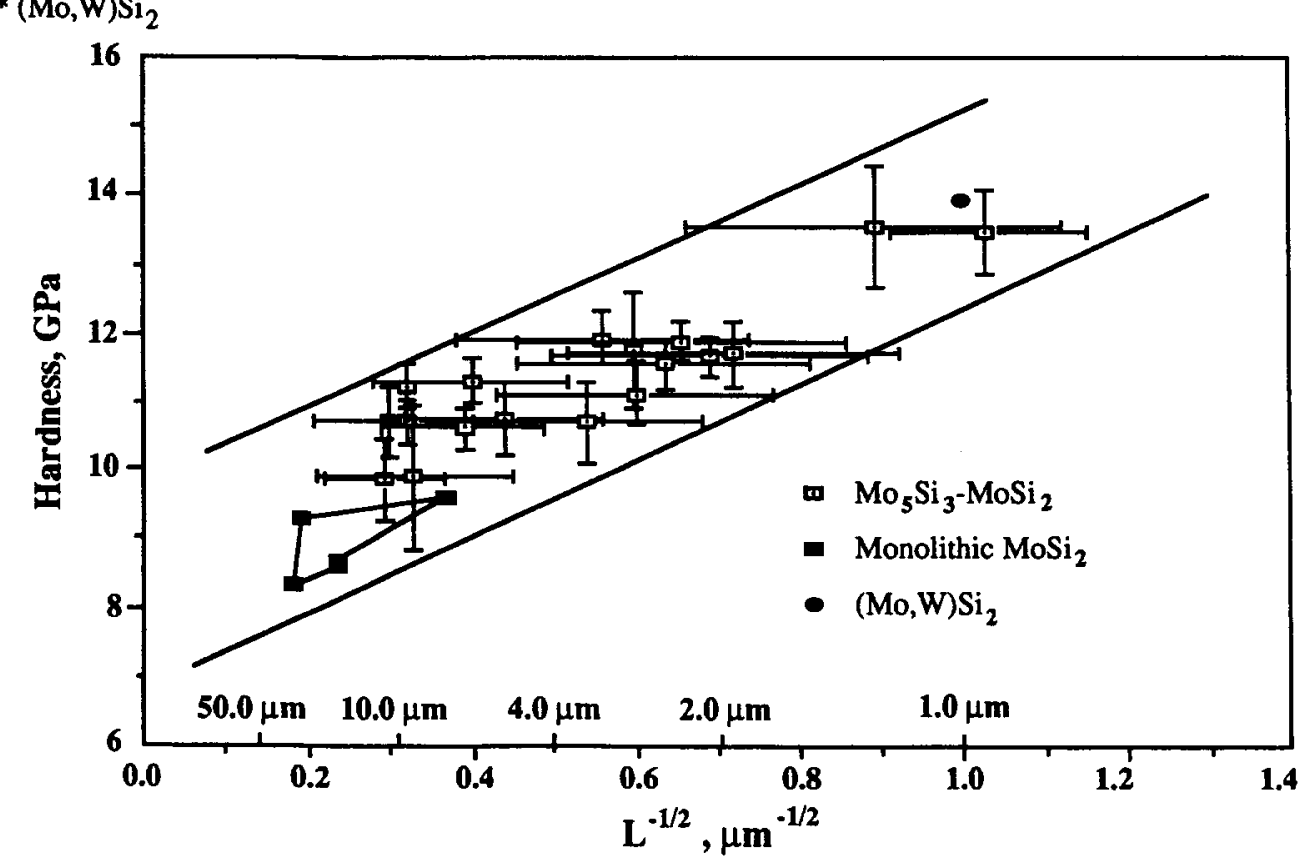

FIG. 4 Plot showing the Hall-Petch relationship between hardness and $\mathrm{L}^{-1 / 2}$, where $\mathrm{L}$ refers to the nominal width of the $\mathrm{MoSi}_{2}$ phase in the lamellar eutectic and grain size in monolithic MoSi 2 and (Mo,W)Si2. Also, note that the room temperature hardness values for monolithic $\mathrm{MoSi}_{2}$ and $(\mathrm{Mo}, \mathrm{W}) \mathrm{Si}_{2}$ fall within the linear band of the eutectic material.

Hardness and $\mathrm{MoSi}_{2}$ Size as a Function of Processing and $\mathrm{Er}$ Concentration in $\mathrm{MqSi}_{3}-\mathrm{MoSi}_{2}$ Materials

\begin{tabular}{|c|c|c|c|}
\hline Sample & $\begin{array}{c}\mathrm{MoSi}_{2} \text { Size } \\
(\mu \mathrm{m})\end{array}$ & At \% Er & $\begin{array}{c}\text { Handness } \\
(\mathrm{GPa})\end{array}$ \\
\hline \multirow{2}{*}{ ACP } & $0.93 \pm 0.20$ & 0.00 & $13.47 \pm 0.62$ \\
& $3.10 \pm 2.10$ & 0.35 & $11.91 \pm 0.39$ \\
\hline & $1.25 \pm 0.65$ & 0.35 & $13.53 \pm 0.89$ \\
& $1.90 \pm 1.20$ & 0.70 & $11.71 \pm 0.49$ \\
$\mathrm{AC}$ & $2.71 \pm 1.50$ & 1.05 & $11.17 \pm 0.47$ \\
& $3.40 \pm 1.84$ & 1.40 & $10.71 \pm 0.61$ \\
& $9.20 \pm 6.00$ & 0.00 & $9.88 \pm 1.04$ \\
\hline \multirow{2}{*}{ DSG } & $2.45+1.40$ & 0.00 & $11.88 \pm 0.31$ \\
& $2.82 \pm 1.49$ & 0.00 & $11.73 \pm 0.84$ \\
\hline \multirow{2}{*}{$\mathrm{DSG}$} & $2.04 \pm 1.16$ & 0.35 & $11.65 \pm 0.28$ \\
& $11.55 \pm 5.6$ & 0.35 & $9.87 \pm 0.59$ \\
\hline \multirow{2}{*}{$\mathrm{DS}$} & $5.01 \pm 2.90$ & 0.00 & $10.75 \pm 0.55$ \\
& $6.56 \pm 3.40$ & 0.00 & $10.61 \pm 0.31$ \\
\hline \multirow{2}{*}{ HP } & $8.00 \pm 5.00$ & 0.00 & $10.70 \pm 0.34$ \\
& $6.10 \pm 3.75$ & 0.35 & $11.38 \pm 0.34$ \\
\hline
\end{tabular}

m $\mathrm{Mo}_{5} \mathrm{Si}_{3}-\mathrm{MoSi}_{2}$

- Monolithic $\mathrm{MoSi}_{2}$

- $(\mathrm{Mo}, \mathrm{W}) \mathrm{Si}_{2}$ 
effective in improving the elevated temperature strength of MoSi2; however, improvements in compressive creep strength have yet to be realized in these materials despite the reported higher hot hardness (2). This difference may in part be due to microcracking during the mechanical tests which is suppressed by the hydrostatic stress fields generated during hardness testing. It should be noted, as shown in FIG. 3 , that as the scale of the lamellar eutectic is decreased a higher load can be sustained. Here the laminated structure of the eutectic produces a more tortuous crack path as a result of crack deflection and thus, a refined lamellar eutectic microstructure may provide higher fracture toughness.

It is interesting to note that the hardness values reported for monolithic MoSi2 also fall in the hardness band shown for the eutectics in FIG. 4. However, the hardness of these polycrystalline materials are in general lower than those reported for single crystals (see Table I). Based upon our work we believe these lower hardness values are associated with processing defects, e.g. porosity and the presence of $\mathrm{SiO}_{2}$. Additions of erbium however do not significantly affect either the intrinsic hardness or the composite hardness. Thus, the hardness difference originally reported by Gibala et al (2) for the MoSi2-Mo5Si3 eutectic was related to microstructural scale rather than a solid solution effect or the elimination of $\mathrm{SiO}_{2}$ from the melt.

\section{Conclusions}

The room temperature hardness of $\mathrm{MoSi}_{2}-\mathrm{Mo}_{5} \mathrm{Si} 3$ eutectics has been shown to follow a Hall-Petch relationship indicating that the strength of MoSi2-based materials can be significantly affected by microstructural scale. A similar trend was demonstrated for monolithic $\mathrm{MoSi}_{2}$ using the values of grain size and hardness reported in the literature.

\section{Acknowledgments}

This work was supported in part by the Air Force Office of Scientific Research under the AFOSR-URI grant No DoD-G-AFOSR-90-0141. The program manager was Dr. Alan H. Rosenstein. Also, the authors gratefully acknowledge Mr. Jim Garrett of McMaster University for providing the two Czochralski directionally solidified samples.

\section{References}

1. D. E. Alman, K. G. Shaw, N. S. Stoloff and K. Rajan, Mat. Sci. and Eng. A155, 95 (1992)

2. R. Gibala, A. K. Ghosh, D. C. Van Aken, D. J. Srolovitz, A. Basu, H. Chang, D. P. Mason and W. Yang, Mat. Sci. and Eng. A155, 147 (1992).

3. S. M. Wiederhorn, R. J. Gettings, D. E. Roberts and C. Ostertag, Mat. Sci. and Eng. A155, 147 (1992).

4. R. M. Aiken, Scripta Metall. 26, 1025 (1992).

5. J. H. Westbrook, Intermetaliic Compounds, Robert E. Krieger Publishing Co., New York, p. 471 (1977).

6. R. Tiwari and H. Herman, Mat. Sci. and Eng. A155, 95 (1992).

7. S. Maloy, A. H. Heuer, J. Lewandoski and J. Petrovic, J. Am. Ceram. Soc. 74, 2704 (1991).

8. R. G. Castro, R. W. Smith, A. D. Rollett and P. W. Stanek, Scripta Metall. 26, 207 (1992)

9. R. Keiffer and E. Cerwenka, Z. Metallkunde 43, 101 (1952)

10. I. E. Campbell, High -Temperature Technology, p. 164, John Wiley \& Sons Inc., New York (1956).

11. R. K. Wade, J. Am. Ceram. Soc. 75, 1682 (1992).

12. R. B. Schwartz, S. R. Srinivasan, J. J. Petrovic and C. J. Maggiore, Mat. Sci. and Eng. A155, 75 (1992).

13. A. Bhattacharya and J. Petrovic, J. Am. Ceram. Soc. 74, 2700 (1991)

14. D. P. Mason, D. C. Van Aken and J. F. Mansfield, submitted to J. Mat. Res.

15. P. H. Boldt, J. D. Embury and G. C. Weatherly, Mat. Sci. and Eng. A155, 251 (1992). 